\title{
М.Г.Ростовцев ${ }^{1}$ Н.А.Кол ${ }^{2}$ А.Ф.Чульдум ${ }^{2}$ Ю.А.Калуш ${ }^{2}$ \\ РЕЗУЛЬТАТИВНОСТЬ ВЫЯВЛЕНИЯ ЭПИЗООТИЙ ЧУМЫ ПРИ ИССЛЕДОВАНИИ РАЗЛИЧНОГО ПОЛЕВОГО МАТЕРИАЛА В ТУВИНСКОМ ПРИРОДНОМ ОЧАГЕ (КАРГИНСКИЙ МЕЗООЧАГ)
}

\author{
${ }^{1}$ ФГУЗ «Тувинская противочумная станция», \\ ${ }^{2}$ Тувинский институт комплексного освоения природных ресурсов СО РАН, Кьзыл
}

\begin{abstract}
На основе анализа многолетних данных, полученных в Каргинском мезоочаге Тувинского природного очага чумы, определена информативность различных биологических объектов для выявления культур чумы. Подробно изучена динамика эпизоотического процесса по данным исследования массового материала трех основных типов. Полученные результаты дали возможность определить и уточнить оптимальные сроки сбора того или иного полевого материала для лабораторного исследования.
\end{abstract}

Ключевые слова: Тувинский природный очаг чумы, эпизоотологический мониторинг, сроки сбора полевого материала.

В 1964 г. в Туве был открыт природный очаг чумы [8]. С тех пор в республике практически ежегодно регистрируются эпизоотии чумы в МонгунТайгинском и Овюрском районах (юго-западная Тува). За 42 года мониторинга (с 1965 по 2006) сотрудниками Тувинской противочумной станции зарегистрировано около 1,5 тыс. культур этой инфекции. Тувинский природный очаг чумы, вероятно, является северной частью единого очага, расположенного на территории Монголии $[8,11]$, и представляет непосредственную угрозу населению, проживающему на его территории [10].

При поиске эпизоотий лабораторному исследованию подвергались органы теплокровных носителей возбудителя чумы; эктопаразиты, обнаруженные в шерстном покрове зверьков; блохи, собранные в природе из входов нор и при разборе гнезд грызунов и зайцеобразных; а также трупы мелких млекопитающих, найденные на территории очага. В целях оптимизации эпизоотологического мониторинга природного очага чумы нами предпринята попытка оценить результативность исследования массового полевого материала в различные периоды (по датам сбора) среднестатистического эпизоотического сезона.

Общие сроки активизации эпизоотического процесса в Каргинском мезоочаге чумы в настоящее время достаточно хорошо известны $[3,5,6,7,12,13,14]$. Однако отсутствует статистическая оценка информативности исследования разных животных, участвующих в процессе, и характера изменения этой информативности. В связи с этим целью нашей работы было детальное определение оптимальных сроков исследования различного полевого материала.

\section{Материалы и методы}

Территория Тувинского природного очага чумы разделяется на шесть относительно самостоятельных мезоочагов [3]. Для анализа нами выбран Каргинский мезоочаг, где получен наиболее репрезентативный материал. На его территории с 1964 по 2006 год выделено наибольшее количество культур чумы (982), а эпизоотии регистрируются почти ежегодно.

Первичные данные обо всех культурах чумы, выделенных с 1965 по 2006 год на территории этого мезоочага, были внесены в таблицу Excel. Информация в табл. 1 представляет собой вид материала, из которого выделен возбудитель, дату и подробный адрес его сбора. Из табл. 1 с помощью программной выборки были выделены записи, относящиеся к различным объектам лабораторного исследования.

В качестве единицы измерения частоты активизации эпизоотического процесса выбрано количество результативных дней, приходящихся на каждую календарную дату за период работы с 1965 по 2006 год. Под результативным днем подразумевается календарный день работы зоологической группы, в течение которого была выделена одна или более культур чумы. Эта единица измерения уже успешно апробирована для анализа временной изменчивости структуры Каргинского мезоочага чумы $[5,13]$.

\section{Результаты и их обсуждение}

\section{1. Неравноценность полевого материала для обнаружения возбудителя чумы \\ Общее количество результативных дней в} Каргинском мезоочаге за 42 года наблюдений (19652006 ) составляет 376 . В эти дни в Каргинском мезоочаге были выделены 895 культур чумы. Вычленение и суммирование результативных дней, полученных при исследовании различного материала, показало его неравноценность при эпизоотологическом обследовании этого мезоочага.

Как и предполагалось, наибольшее количество результативных дней дало исследование на чуму эктопаразитов, собранных с основного носителя возбудителя - длиннохвостого суслика (Spermophilus undulatus Pallas, 1778). Вторым по эффективности было исследование органов длиннохвостого суслика, 
третьим - эктопаразитов из входов его нор.

Так как исследование второстепенных носителей [монгольская (Ochotona pricei Thomas, 1911) и даурская (Ochotona daurica Pallas, 1776) пищухи, тушканчик прыгун (Allactaga sibirica Forster, 1778), плоскочерепная полевка (Alticola strelzowi Kastschenko, 1899)], трупов мелких млекопитающих и блох из гнезд оказалось гораздо менее результативным при поиске эпизоотий, то в нашей работе основное внимание уделено трем наиболее результативным способам поиска возбудителя чумы.

2. Предварительное салаживание временных рядов для различных видов полевого материала

Для получения трендов использовали данные о количестве результативных дней по каждому из объектов поиска возбудителя чумы. Исходные данные предварительно обработали, используя метод сглаживания динамического ряда по 3 точкам [1]. Предварительная обработка исходного числового ряда была направлена на решение следующих задач (всех или части из них): снизить влияние случайной составляющей в исходном числовом ряду, т. е. приблизить его к тренду; представить информацию, содержащуюся в числовом ряду, в таком виде, чтобы существенно снизить трудность математического описания тренда. Основным методом решения этих задач является процедура сглаживания статистического ряда.

Процедура сглаживания направлена на минимизацию случайных отклонений точек ряда от некоторой гладкой кривой предполагаемого тренда процесса $[2,4]$. Наиболее распространен способ осреднения уровня по некоторой совокупности окружающих точек, причем эта операция перемещается вдоль ряда точек, в связи с чем обычно называется скользящая средняя. В самом простом варианте сглаживающая функция линейна, и сглаживающая группа состоит из предыдущей и последующей точек. В нашем случае к первому значению последовательности чисел применили формулу:

$$
S_{1}=\frac{\left(5 * X_{1}+2 * X_{2}-X_{3}\right)}{6},
$$

Конечное значение последовательности чисел рассчитывалось по формуле

$$
S_{k}=\frac{\left(-X_{k-2}+2 * X_{k-1}+5 * X_{k}\right)}{6},
$$

К остальным значениям последовательности чисел применили формулу

$$
S_{n+1}=\frac{\left(X_{n}+X_{n+1}+X_{n+2}\right)}{3},
$$

где $S_{i}$ - сглаженные значения ряда, $X_{i}-$ значения исходного ряда.
Сглаживание даже в простом линейном варианте является во многих случаях весьма эффективным средством выявления тренда при наложении на эмпирический числовой ряд случайных помех и ошибок измерения. Для рядов со значительной амплитудой помехи имеется возможность проводить многократное сглаживание исходного числового ряда. Число последовательных циклов сглаживания было выбрано в зависимости от вида исходного ряда, от степени предполагаемой его зашумленности помехой и цели, которую преследует сглаживание. В данном случае было применено 26-кратное сглаживание (рис. 1).

Для максимальных значений трендов хода эпизоотий по результатам исследования различного полевого материала определены даты их наибольшей значимости для поиска эпизоотий чумы в мезоочаге (табл. 1).

Незначительное количество культур чумы получено от второстепенных носителей, в основном от монгольской пищухи. Эпизоотии чумы в популяциях этого зайцеобразного регистрировались в период с 1965 по 1969 год. После 70-го года случаи выделения чумы от особей монгольской пищухи единичные.

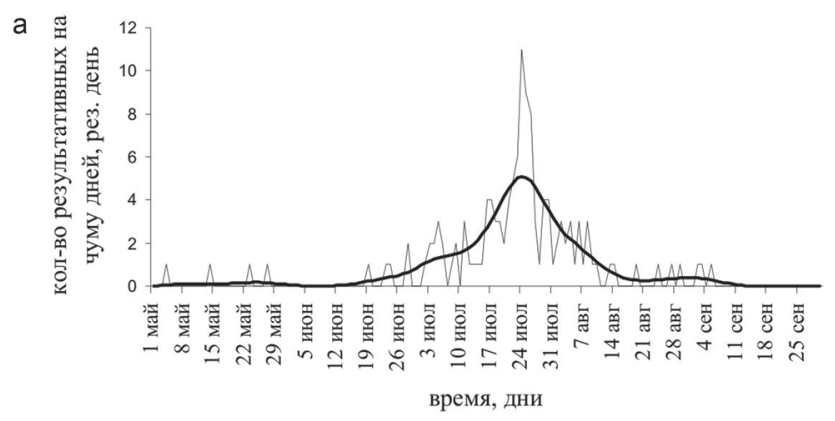

$\sigma$
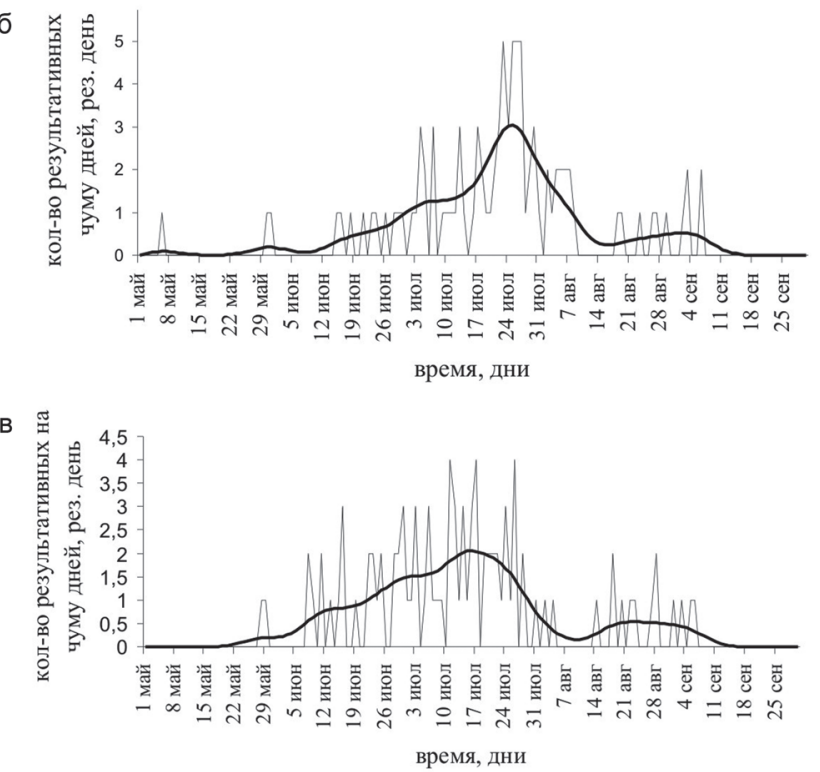

Рис. 1. Среднемноголетний ход эпизоотического процесса в Каргинском мезоочаге чумы (1965-2006 гг.) по результатам исследования различного полевого материала:

— - исходный ряд, — - после процедуры сглаживания; $a$ - эктопаразиты, собранные с длиннохвостого суслика; $\sigma$ - органы длиннохвостого суслика;

в - блохи из входов нор (исходные и сглаженные ряды) 
Таблийа 1

\begin{tabular}{|c|c|c|}
\hline \multicolumn{3}{|c|}{$\begin{array}{c}\text { Даты максимальных значений сглаженных трендов } \\
\text { среднемноголетнего хода эпизоотий чумы } \\
\text { в Каргинском мезоочаге и суммы результативных дней } \\
\text { при исследовании различного полевого материала }\end{array}$} \\
\hline $\begin{array}{l}\text { Объекты поиска } \\
\text { возбудителя чумы }\end{array}$ & $\begin{array}{c}\text { Дата } \\
\text { максимального } \\
\text { значения тренда }\end{array}$ & $\begin{array}{l}\text { Сумма } \\
\text { результативных } \\
\text { дней }\end{array}$ \\
\hline $\begin{array}{l}\text { Эктопаразиты, собранные } \\
\text { с длиннохвостого суслика }\end{array}$ & 24 июля & 130 \\
\hline Органы длиннохвостого суслика & 25 июля & 97 \\
\hline $\begin{array}{l}\text { Блохи из входов нор } \\
\text { длиннохвостого суслика }\end{array}$ & 16 июля & 93 \\
\hline $\begin{array}{l}\text { Трупы и собранные с них } \\
\text { эктопаразиты }\end{array}$ & 25 июля & 26 \\
\hline $\begin{array}{l}\text { Блохи из гнезд грызунов } \\
\text { и зайцеобразных }\end{array}$ & 27 июля & 10 \\
\hline $\begin{array}{l}\text { Эктопаразиты, собранные } \\
\text { с второстепенных носителей }\end{array}$ & 26 июня & 9 \\
\hline $\begin{array}{l}\text { Органы второстепенных } \\
\text { носителей }\end{array}$ & 3 июля & 11 \\
\hline
\end{tabular}

Даты максимумов трендов хода сезонного эпизоотического процесса, когда культуры чумы выделялись от второстепенных носителей и их эктопаразитов, приходятся на начало лета: от блох - 26 июня; от органов теплокровных -3 июля.

3. Математические модели хода сезонного эпизоотического прочесса для трех основных объектов поиска возбудителя чумы

Для трех основных видов полевого материала, используемого для поиска возбудителя чумы (эктопаразиты, собранные с длиннохвостого суслика; органы длиннохвостого суслика; блохи из входов нор), сглаженные ряды аппроксимировали суммой трех гауссовских распределений (4).

$$
\begin{aligned}
& Y=a_{1} * \exp \left(-\left(\frac{X-b_{1}}{c_{1}}\right)^{2}\right)+a_{2} * \exp \left(-\left(\frac{X-b_{2}}{c_{2}}\right)^{2}\right)+ \\
& +a_{3} * \exp \left(-\left(\frac{X-b_{3}}{c_{3}}\right)^{2}\right),
\end{aligned}
$$

где $Y$ - значения количества результативных дней с чумой, $X$ - номер дня обследовательского сезона с

Таблица 2

\begin{tabular}{|c|c|c|c|}
\multicolumn{5}{|}{$\begin{array}{l}\text { Параметры модели суммы трех гауссиан } \\
\text { для трех основных объектов поиска чумы }\end{array}$} \\
\begin{tabular}{|c|c|c|c} 
Коэффициент \\
модели
\end{tabular} & $\begin{array}{c}\text { Эктопаразиты, } \\
\text { собранные } \\
\text { слиннохвостого } \\
\text { суслика }\end{array}$ & $\begin{array}{c}\text { Органы } \\
\text { длинохвостого } \\
\text { суслика }\end{array}$ & $\begin{array}{c}\text { Блохи } \\
\text { изодов нор }\end{array}$ \\
\hline $\mathrm{a}_{1}$ & 1,3 & 1,2 & 1,25 \\
$\mathrm{a}_{2}$ & 4,4 & 2,2 & 1,36 \\
$\mathrm{a}_{3}$ & 0,35 & 0,49 & 0,55 \\
$\mathrm{~b}_{1}$ & 72 & 72,5 & 62 \\
$\mathrm{~b}_{2}$ & 86 & 87 & 80,5 \\
$\mathrm{~b}_{3}$ & 123 & 123,8 & 118 \\
$\mathrm{c}_{1}$ & 17 & 24 & 23 \\
$\mathrm{c}_{2}$ & 9,5 & 9,05 & 10,2 \\
$\mathrm{c}_{3}$ & 9,34 & 11,05 & 13 \\
\hline
\end{tabular}

1 мая по 30 сентября (1-153-й день). Параметры модели $a_{1}, a_{2}, a_{3}, b_{1}, b_{2}, b_{3}, c_{1}, c_{2}, c_{3}$ суммы гауссовских распределений для основных объектов поиска чумы представлены в табл. 2. Коэффициент детерминации $R^{2}$ этого уравнения и исходного не сглаженного ряда составляет: для эктопаразитов, собранных с длиннохвостого суслика, $-0,7$; для органов длиннохвостого суслика $-0,6$; для блох из входов нор $-0,5$.

Полученные тренды (рис. 2) хорошо выявляют сезонные особенности течения эпизоотического процесса. При этом заметно, что тренды трех основных объектов исследования сдвинуты во времени. Даты максимума для эктопаразитов, собранных с длиннохвостого суслика, -24 июля, для органов длиннохвостого суслика -25 июля, для блох из входов нор - 16 июля. Начало активизации эпизоотического процесса в июле совпадает по времени с моментом среднемноголетнего начала расселения молодняка длиннохвостого суслика и предположительно описывает влияние расселения на ход эпизоотий. По наблюдениям зоологов [15], именно в этот промежуток времени увеличивается активность молодых зверьков по поиску свободных нор, которые зачастую населены инфицированными чумой эктопаразитами. С этим природным явлением непосредственным образом и связано резкое возрастание интенсивности эпизоотий в Каргинском мезоочаге Тувинского природного очага чумы.

Также заметно, что осенний пик имеет невысокую сглаженную форму и приходится на конец августа. Детальный анализ записей, отражающих количество рабочих дней, проведенных зоогруппами в мезоочаге с 10 августа по 30 сентября, показал, что это явление вполне объективно и не зависит от действий руководителя зоогруппы, то есть от субъективного фактора. Если основной пик достаточно хорошо объясняется жизнедеятельностью основного носителя, в частности, сезонным ходом его миграционной активности, то причина второго осеннего пика в настоящее время не ясна.

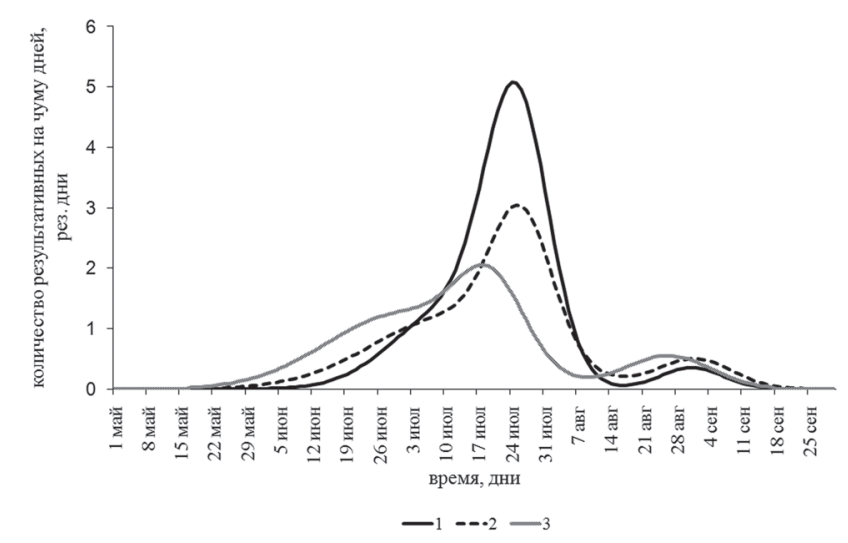

Рис. 2. Графики математической модели хода эпизоотического процесса, выявляемого по результатам исследования различного полевого материала:

1 - эктопаразиты, собранные с длиннохвостого суслика;

2 - органы длиннохвостого суслика; 3 - блохи из входов нор 
Выяснилось, что кривые, характеризующие частоту регистрации возбудителя чумы (рис. 2), отличаются между собой не только абсолютными значениями максимумов и временем их проявления, но и величиной коэффициента эксцесса. Эксцесс характеризует относительную остроконечность или сглаженность распределения по сравнению с нормальным распределением. Высокий коэффициент эксцесса для кривых, относящихся к лабораторному исследованию органов длиннохвостого суслика $(1,44)$ и эктопаразитов его шерсти $(1,39)$, еще раз косвенно подтверждает положительное влияние июльского расселения этого грызуна на частоту регистрации чумы. Коэффициент эксцесса кривой для блох, собранных из входов нор, напротив, меньше и равен 1,01, что говорит о сглаженности хода эпизоотического процесса, выявленного по этому материалу.

\section{4. Значение полученных результатов}

Полученные результаты имеют не только теоретическое, но и практическое значение. Еще в 1972 г. Г.С.Летов в своей работе [9] показал, что наиболее продуктивным способом поиска микроочагов чумы в начале лета является сбор блох из входов нор длиннохвостого суслика. Наша работа подтверждает его предположение и дает более детальную картину эпизоотического процесса при использовании различной тактики поиска возбудителя чумы. Нами конкретизированы границы отрезков времени, в течение которых необходимо существенно увеличивать сбор того или иного полевого материала при поиске микроочагов чумы в Каргинском мезоочаге.

Сбор блох из входов нор длиннохвостого суслика предпочтителен с 4 июня по 13 июля, с 14 июля по 17 августа основную роль должен играть отлов и очес особей основного носителя. В то же время 3оогруппам, осуществляющим эпизоотологическое обследование, вплоть до 29 июля не следует полностью отказываться от сбора блох из входов нор, так как материал, полученный этим способом до указанной даты, все еще дает неплохие результаты по поиску чумы в данном мезоочаге.

В целом полученная картина отражает ход переноса чумного микроба в цепи его передачи от переносчика к основному носителю: от блох из входов нор (максимум 16 июля) к эктопаразитам шерсти длиннохвостого суслика (максимум 24 июля) и от них к длиннохвостому суслику (максимум 25 июля). В конце августа - начале сентября этот процесс повторяется со значительно меньшей интенсивностью.

Таким образом, в результате статистического анализа многолетних данных, собранных в Каргинском мезоочаге Тувинского природного очага чумы, было установлено, что наибольшее количество результативных дней дало исследование эктопаразитов, собранных с длиннохвостого суслика, органов зверька и блох из входов его нор; первым выявляет активизацию Каргинского мезоочага исследование блох из входов нор (максимум 16 июля); вторым - эктопара- зитов, собранных с суслика (максимум 24 июля); третьим - органов длиннохвостого суслика (максимум 25 июля); математическая модель трех основных тактических приемов выявления эпизоотического процесса может быть представлена в виде суммы трех гауссовских распределений и описывает три различных биологических процесса. Один - с плавным длительным течением, второй - кратковременный и интенсивный и третий (осенняя активизация) - наименьший.

Начиная с 2006 г. результаты анализа были непосредственно внедрены в практику работы Тувинской противочумной станции. На основании полученных данных изменена тактика обследования Каргинского мезоочага, в том числе изменены показатели территориально-календарного плана полевых работ. До 2006 г. зоогруппы на протяжении всего сезона одновременно проводили как отлов суслика, так и сбор блох из входов его нор. Этот процесс был трудоемок и, как выяснилось, не всегда оправдан. С 2006 г. эпизоотологическое обследование стали проводить в два тура. Во время первого тура для быстрейшего выявления эпизоотии делают упор на сбор блох из входов нор основного носителя. Во втором туре преимущественно проводят отлов и исследование длиннохвостого суслика и собранных с него эктопаразитов. Использование такой тактики позволило улучшить качество эпизоотологического обследования, а также снизило антропогенный пресс на популяцию длиннохвостого суслика.

Работа поддержана грантом Российского фонда фундаментальных исследований проект № 07-0596812 p_енисей_а.

\section{СПИСОК ЛИТЕРАТУРЫ}

1. Андерсон Т., перевод Журбенко И.Г., Носко В.П., редактор Беляев Ю.К. Статистический анализ временных рядов. М.: Мир; 1976.744 с.

2. Баранов B.A. Общие вопросы методологии и научного прогнозирования. Харьков; 1992. 230 с

3. Вержуикий Д.Б., Окунев Л.П., Попков А.Ф., Иннокентьева Т.И., Косилко С.А., Базанова Л.П. и др. Методические рекомендации по эпизоотологическому обследованию Тувинского природного очага чумы. Иркутск; 2004. 19 с.

4. Зенкин А.И. О математических методах прогнозирования. М.; 1987.90 с

5. Кол Н.А., Ростовиев М.Г., Чульдум А.Ф. Оптимизация сроков эпизоотологического обследования Каргинского мезоочага Тувинского природного очага чумы. Бюл. ВосточноСибирского научного центра СО РАМН. Иркутск; 2008. 6(64): 25-9.

6. Крюков И.Л. Взаимосвязь сезонной жизнедеятельности длиннохвостого суслика и блохи Ceratophyllus tesquorum в Тувинском природном очаге чумы. В кн.: Совр. асп. профилакт. зоонозных инф.: Тез. докл. к Всесоюзн. науч. конф. специалистов противочумн. учрежд. Иркутск; 1984. Ч. 1. С. 85-7.

7. Кузнеиов В.И., Крюков И.Л., Саржинский В.А. Материалы к эпизоотологической характеристике Монгун-Тайги. Докл. Иркут. противочумн. ин-та Сибири и Дальн. Вост. Кызыл, 1969; $8: 25-8$.

8. Летов Г.С. Хархира-Монгунтайгинский участок Алтайского очага чумы. Пробл. особо опасных инф. 1969; 2(6):37-45.

9. Летов Г.С., Летова Г.И., Мамонтова Э.В. К вопросу о методике эпизоотологической разведки в Туве. Пробл. особо опасных инф. 1972; 2(24):132-6.

10. Онишенко Г.Г, Кутырев В.В., редакторы. Природные очаги чумы Кавказа, Прикаспия, Средней Азии и Сибири. М.; 2004. 192 c.

11. Равдоникас И.О. К истории становления очага чумы 
Каргинской котловины. Докл. Иркут. противочумн. ин-та Сибири и Дальн. Вост. Чита, 1974; 10:54-6.

12. Родионов А.А., Феоктистов А.З. Современное состояние Тувинского природного очага чумы. Докл. Иркут. противочум. ин-та Сибири и Дальнего Востока. Чита, 1974; 10:51-4.

13. Ростовиев М.Г., Хомушку Е.Ч., Калуш Ю.А, Чульдум

$A . \Phi$. Новый подход к оценке сезонной активности Каргинского участка очаговости Тувинского очага чумы Бюллетень ВосточноСибирского научного центра СО РАМН. Иркутск, 2004; 1(2): 157-60.

14. Устюжина И.М., Равдоникас И.О., Устюжин Ю.А. и др. Некоторые итоги изучения Тувинского природного очага чумы (1964-1974 гг.). Сообщение 2. Биоценотическая структура очага: Тез. докл. науч. конф. Междунар. и нац. аспекты эпиднадзора при чуме. Иркутск; 1975. Вып. 1. С 52-7.

15. Шилова С.А., Шилов И.А., Левина Л.Е., Родионова Е.И. Некоторые черты пространственно-этологической структуры популяции длиннохвостого суслика (Citellus undulatus Pall.) и попытки ее направленного изменения. Зоол. журн. 1979; 58(7):1042-6.

\section{Об авторах}

Ростовиев М.Г. Тувинская противочумная станция. 667000 Республика Тыва, г. Кызыл, ул. Калинина, 5а.

Кол Н.А., Чульдум А.Ф., Калуш Ю.А. Тувинский институт комплексного освоения природных ресурсов СО РАН. 667007, Республика Тыва, г. Кызыл, ул. Интернациональная, 117-a. E-mail: Natachakol@yandex.ru
M.G.Rostovtsev, N.A.Kol, A.F.Chouldum, Ju.A.Kalush

Effectiveness of Plague Epizootics Detection upon Investigation of Different Field Material in Tuvinian Natural Focus (Karginsk Mesofocus)

Tuvinian Plague Control Station; Tuvinian Institute for Complex Exploration of Natural Resources, SB of the RAS, Kyzyl

Informational value of different biological objects in view of plague agent detection was determined on the basis of analysis of long-term data received in Karginsk' mesofocus of Tuvinian natural plague focus. The dynamics of epizootic process was studied in detail based on the investigation of mass material of three basic types. The results received enabled to determine and clarify the optimal terms of gathering of various field material for laboratory investigations.

Key words: Tuvinian plague natural focus, epizootiologic monitoring, terms of gathering of field material.

Authors:

Rostovtsev M.G. Tuvinian Plague Control Station. 667000, Tuva Republic, Kyzyl, Kalinina St., 5a.

Kol N.A., Chouldum A.F., Kalush Ju.A. Tuvinian Institute for Complex Exploration of Natural Resources, SB of the RAS. 667000, Tuva Republic, Kyzyl, Internationalnaya St., 117-a. E-mail: Natachakol@yandex.ru

Поступила 01.06.09. 